\title{
ONE HUNDRED YEARS OF ORIGINALITY, QUALITY AND STYLE
}

\author{
by \\ CHRISTIAN B. ANFINSEN \\ Laboratory of Chemical Biology \\ National Institute of Arthritis, Metabolism, and Metabolic Diseases \\ National Institutes of Health, Bethesda, Maryland 20014, U.S.A. \\ Lecture given at the Centennial of the Carlsberg Laboratory, \\ Copenhagen, September 27, 1976
}

My choice of a title for this short lecture on the Carlsberg Laboratory and its impact over the years was made after a lot of thought about why some centers of science become international Meccas and so many others never quite make it. Thousands of scientists ponder the problem of where they might best go to attain professional breadth and skill in their specialty. It is generally fairly easy to give advice to such individuals. At any given time, certain scientific centers stand out in everyone's mind: the MRC lab at Cambridge, with its glittering constellation of stars, the Pasteur Institute in the exciting and fermenting days of $\mathrm{JACOB}_{\mathrm{B}}$ and MONOD at their best, OTTO WARBURG's laboratory in the twenties and thirties when the machinery of metabolism first began to be studied in detail, and my own institution, the NIH, during the days of the Vietnam doctor draft when we were able to help a large group of bright, young MD's to stay out of a senseless war. To protein chemists (omitting of course X-ray crystallographers who travelled elsewhere), the name of the Carlsberg Laboratory has for many years been synonymous with the initiation, prediction or implementation of research in this particular field. It also happens to be in Copenhagen, which gives an initial advantage. In the days of the first director, JOHAN KJELDAHL, I suppose this did not really apply. International travel grants had not been invented and the level of science in the Western Hemisphere and in Asia had not yet benefited from the individuals and ideas that were subsequently to come from Europe and Great Britain. However, from the time of SøRENSEN to the present, almost every protein-oriented laboratory in the world has been flavored with the scientific spices that itinerant students brought home from Copenhagen. As I will try to illustrate to you shortly, using examples from my own scientific career, the conscious or subconscious choice made in research direction or emphasis has frequently been the product of the Carlsberg Laboratory's intellectual flavor.

Let me first say a few things about the history of 
the laboratory. As you all know, four directors have guided the progress and tone since 1876 when JACOB CHRISTIAN JACOBSEN had his altruistic idea: JohaN KJEldahl, S. P. L. SøRENSEN, KaJ UlRIK LINDERSTR øM-LANG and MARTIN OTTESEN. KJELDAHL's contributions were outstanding, particularly in the context of protein chemistry in the 1880 's. He is, of course best known for his development of precise methods of analysis for nitrogen, in proteins, and biological material in general, and later for his studies on the enzymes concerned with fermentation of sugars. I have a feeling that KJELDAHL would have been very happy about the construction of the fine new center being dedicated today and tomorrow. He clearly had natural instincts for what we might now call applied science and a good deal of his efforts were directly or indirectly concerned with processes or problems emerging from the phenomenon of fermentation. The impact of his analytical methods has been universally felt. I can testify that I have had a stomach full of doing "Kjeldahls" in my own lab experience.

SøRENSEN was perhaps more the kind of scientist that we generally associate with Carlsberg. I never had the fortune to meet him, but from what I have read and acquired through generous conversations with HERMANN KALCKAR and others, he had a quiet, gentlemanly and unruffled mentality. To my mind, he and his successors introduced the almost anthropomorphic feeling many of us now have about protein molecules; objects deserving careful love and attention because of their role as the direct expression of the DNA tapes that have developed through natural selection and evolution. It was characteristic of SøRENSEN, I gather, to shrug off the idea of "publish or perish." $\mathrm{He}$ worked along in a tranquil and thoughtful way until an entire book could be written that would introduce many of our present concepts of the electrical properties of proteins: the $\mathrm{pH}$ scale, isoionic and isoelectric points, the phenomena controlling the nature of titration curves, etc. In his classical paper on the Ionisation of Proteins in 1924, LINDERSTRøM-LANG mentions SøRENSEN's contributions to the field: "This idea has often been impressed upon me by SøRENSEN himself.
- - in ovalbumin we have a substance with many acid and basic groups, whose dissociation constants do not lie far apart, and whose dissociation curves therefore partly overlap and efface each other." My professor, A. BAIRD Hastings, always emphasized to us, as Ph.D. students in his laboratory at Harvard Medical School, that whenever an experiment went wrong we should first check the $\mathrm{pH}$. I must say that this practical application of SøRENSEN's ideas has been at the root of some trouble or other in an incredible number of my own experiments.

SORENSEN also began some of the tradition that I think of as the Carlsberg "mystique." Both Rollin Hotchkiss and Hermann Kalckar have described to me the frequent meanderings of the Professor through the laboratory, when he made himself "available " to his colleagues and to visitors who sought his advice. This casual and friendly approach to daily contact and communication was, of course, enhanced by the fact that the laboratory was not a large, sprawling building crammed with expensive scientific devices but rather of a modest size and so equipped that each investigator did not have his own Model L centrifuge and scintillation counter (or for that matter, his own set of beakers). While waiting for a piece of equipment, or for the community $5 \mathrm{ml}$ pipette, to become available, one actually had some time to think and plan and talk with colleagues so that experiments tended to become somewhat more carefully designed than they frequently are now in these days of easy triplicates. LANG and HEINZ Holter continued and expanded this tradition and there were already signs in 1955, during our last sabbatical visit, that MARTIN OTTESEN also appreciated the value of the "wandering, friendly host" as an important part of what $I$ have referred to in my title as "style."

LANG used to scare me half to death with his fluent translations and treatments of our questions into elegant, mathematical form. He once told me, very generously I am afraid, that most matters could be described in words and sentences as well as by equations. To this day I remain convinced that a few mathematically-endowed scientists, like LANG, simply have 
better-designed brain circuits.

HEINZ HOLTER contributed much to the atmosphere by his personal attention to instruction of new visitors. These were the exciting days of the late 30's period of the development of ultramicro methods which he and LANG devised to make possible the quantitative study of intracellular structure and tissue organization versus enzyme activity. However, HEINZ occasionally became somewhat sadistic. One trick he employed was to "plant" melodies by walking through the lab, quietly whistling or humming a particularly insidious phrase from a Mozart or Bach composition. By the end of an afternoon I would often hear one of my nearby companions repeating the tune that had been running through my own head all day.

It is great sport to sit with one's fellow alumni and reminisce about the days that were shared in this warm and intellectually vigorous atmosphere. I have often played this game with my own contemporaries - HARRINGTON, SCHELlMAN, RICHARDS, IEUAN HARRIS, KAUZMANN, LOWRY, ZAMECNIK, LUMRY and many others. However, the main thing to emphasize about the Carlsberg laboratory is its fundamental scientific contributions to the field of protein chemistry. First came the description of the electrical properties of proteins, studied experimentally by SøRENSEN, and treated in classical style by LANG in the context of the DEBYE-HuCKEL theory. Much of the thinking of the COHN and EDSALL group at Harvard and of the KirkwOOD-ONSAGER School at Yale was related to these ideas.

Perhaps the most critical of the studies carried out by LANG and his colleagues HoTCHKISS, Gordon Johansen, Cecil Jacobsen, OtTeSEN, and a host of subsequent visitors, were concerned with work on the proteolytic digestion of proteins. This long series of experiments which began in the 1930's and were again initiated after the war years, included the study of volume contraction during peptide bond cleavage, and the "limited digestion" observations that led to the concepts of "motility" and "cooperativity، of protein structures in solution. All this, in turn, inspired the techniques for measuring the exchangeability of hydrogen atoms in proteins, and the appearance of titratable groups, as these parameters reflected the cooperative stabilization of organized substructures within the macromolecules.

Rather than discussing, in a chronological way,



Figure 1. The amino acid sequence of staphylococcal nuclease $(3,2)$. 
the scientific contributions from the Carlsberg Laboratory, let me describe a simplified 1976 view of the globular proteins and illustrate how much of this view was already anticipated in the thinking in Copenhagen. The polypeptide backbone of a protein is, of course, simply a repetition, in amino acid language, of the recipe given in the corresponding DNA sequence of bases. The amino acid sequence of a simple, globular protein is shown in Figure 1.

This protein has no cross linkages, no adornments with prosthetic groups, nor modified side chains. Protein sequences were not available in the 20's and 30's, although it was already relatively certain that proteins were well defined chemicals and not arbitrary conglomerates. NORTHROP and SUMNER had already crystallized pepsin and urease and SVEDBERG's precise molecular weight measurements were already well underway. 'Staph. nuclease crystallizes nicely (Figure 2) and is therefore susceptible to X-ray crystallographic analysis for the determination of three-dimensional structure, shown in Figure 3 in highly schematic form.

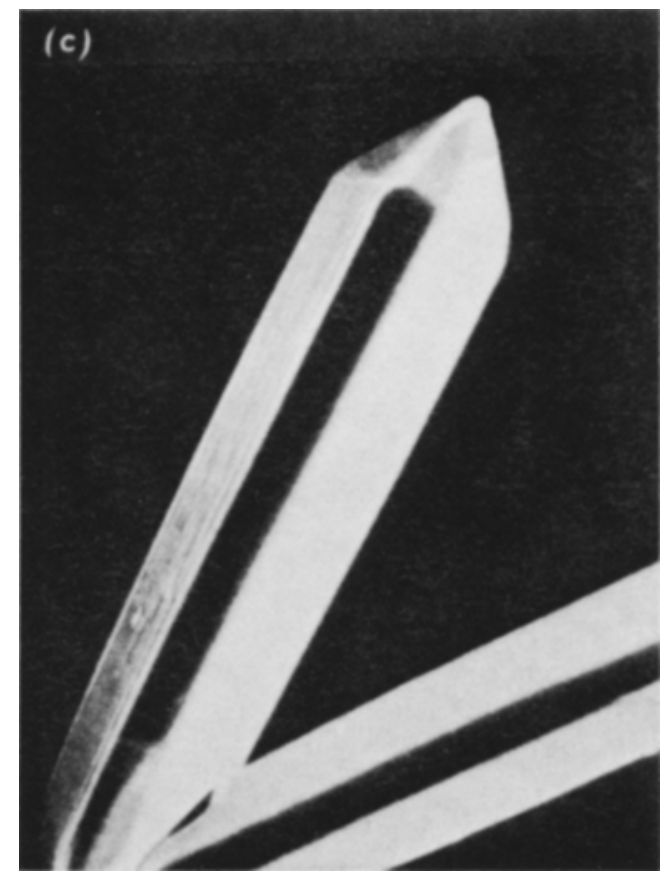

Figure 2. Crystals of nuclease complexed with calcium and $3^{\prime}-5^{\prime}$ - thymidine diphosphate $(1,6)$.

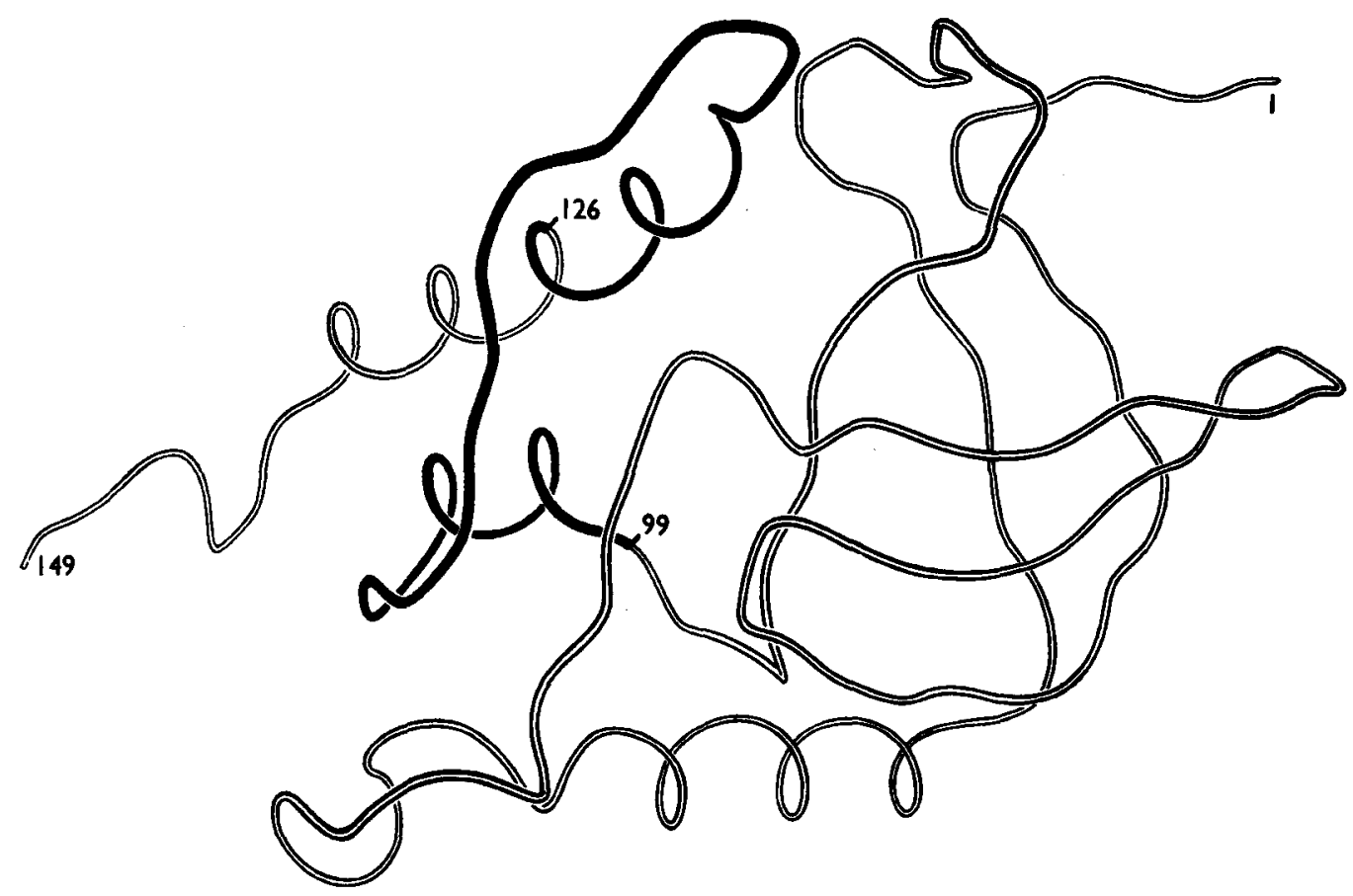

Figure 3. Schematic drawing of three-dimensional arrangement of the polypeptide backbone in staphylococcal nuclease (1). 
Note the organization of this structure; helices, pleated sheets, floppy ends, projecting loops. Furthermore, every molecule is essentially like every other in the crystal (or in solution). LANG et al. designed many of their experiments around the idea of an equilibrium between the tightly coiled native structure, and a population of denatured forms. Let me quote a paragraph in the review that LANG and JOHN SCHELLMAN published in "The Enzymes" in 1959. "The important point is that the ordering forces of the peptide hydrogen bonds appear to be slightly over-compensated by the entropy of unfolding so that the final decision rests on the side-chain interactions which depend themselves on the native sequence of the amino acids present. Since sequences are in general quite aperiodic these forces will be favorable in one part of the molecule, unfavorable in another, so that the protein molecule will often consist of a number of regions of varying structures and stability..."

It is easy to show the internal stabilization of a structure is essentially balanced on the head of a pin. If one looks at stability of structure in solution as a function of $\mathrm{pH}$, for example, a clear, unmistakable cooperativity is easily demonstrated (Figure 4).

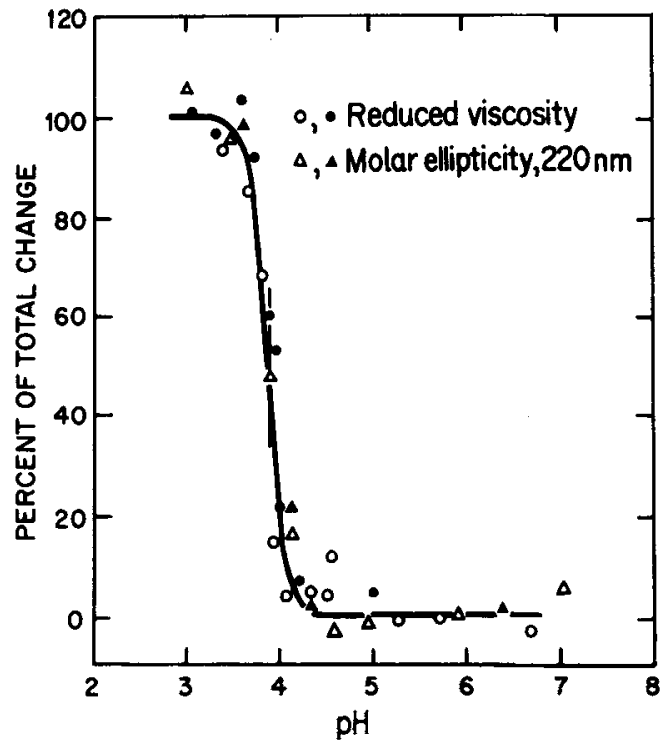

Figure 4. Changes in the reduced viscosity and the molar ellipticity at $220 \mathrm{~nm}$ of nuclease solutions as a function of $\mathrm{pH}$. The abrupt change occurring over a very narrow $\mathrm{pH}$ range are indicative of the cooperativity involved in the folding and stabilization of the native protein (4).
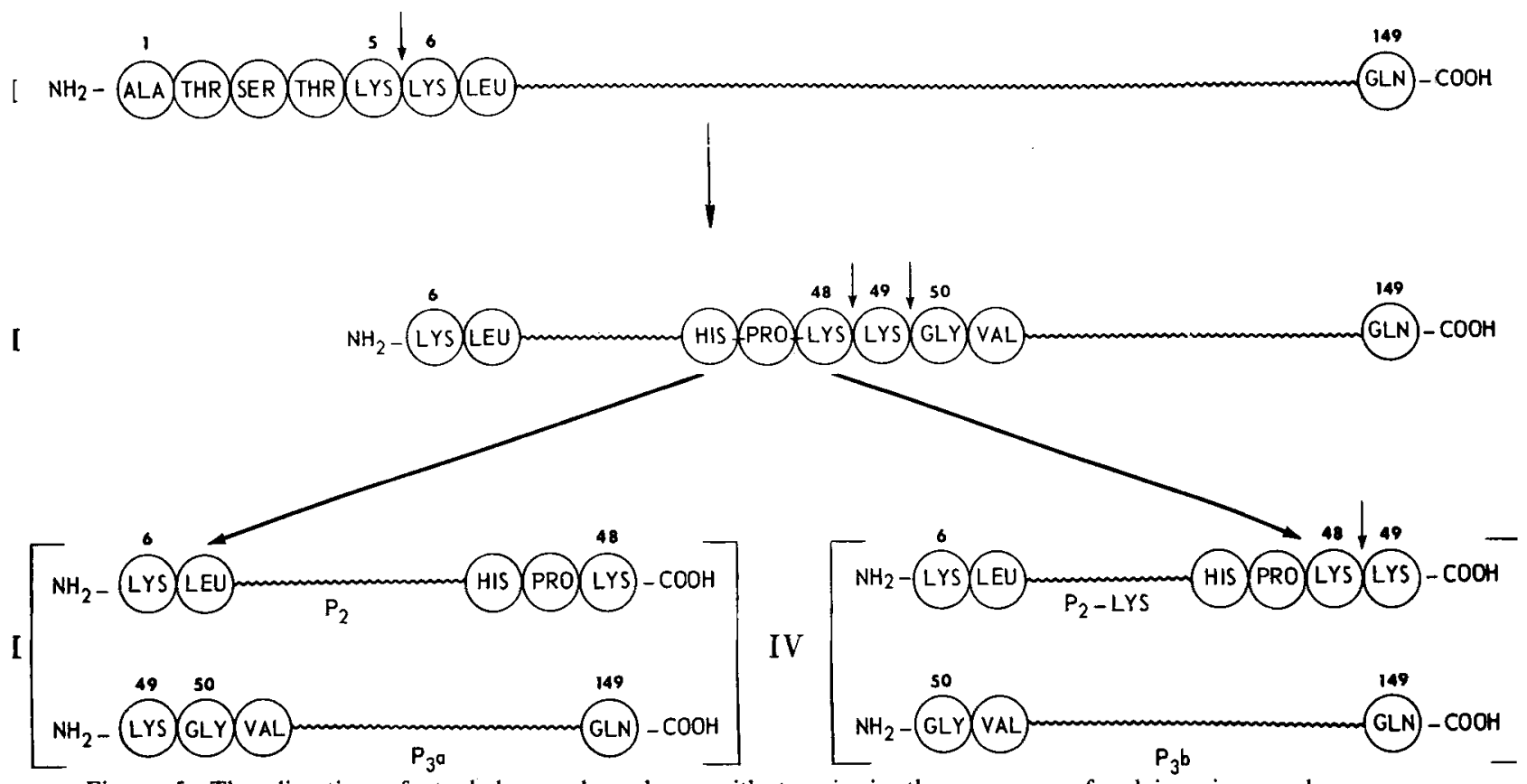

Figure 5. The digestion of staphylococcal nuclease with trypsin in the presence of calcium ions and $3^{\prime}-5^{\prime}$-thymidine diphosphate. Bonds cleaved under these conditions are indicated by the small arrows. Cleavage at other points in the chain is essentially absent due to the strong stabilization of the three-dimensional structure by the ligands (5). 
This inherent instability ("breathing") was measured directly by LANG together with AASE HVIDT and others by measuring the rate at which backbone hydrogen atoms in the native protein would exchange with solvent water hydrogens. The concept of "motility" came directly from these ideas and experiments.

Another way of estimating the deviation of a protein in solution from its normally coiled up form is by measuring susceptibility to proteolytic attack. Returning to Staph. nuclease, we see in Figure 5 how the addition of specifically bound $\mathrm{Ca}^{++}$ions and substrate analogues rigidify and stabilize against major digestion. However, there is some cleavage.

Here again we return to historical anticipation at the Carlsberg laboratory. MARTIN OTTESEN, at one point, decided to crystallize some well aged ovalbumin that had managed to avoid rotting in the cold room because of a protective layer of kerosene. To his surprise he obtained lovely plates rather than the usual ovalbumin needles. This was the discovery of the ovalbumin-plakalbumin conversion, the chemistry of which was subsequently worked out by OTTESEN and LANG in collaboration with several other foreign visitors, including VALLEE and STEINBERG. Here was the first example of a "limited cleavage," outside the zymogen group of proenzymes, of course. The crystal structure of ovalbumin has unfortunately not yet been solved. However, I am sure that we would all be surprised if there were not a bit of the chain extending out from the main body of the molecule, in a sense asking for trouble in the form of a nearby protease (in this case, subtilisin, which was isolated from the $B$. subtilis organisms inhabiting the "ripe" protein solution.) In some cases, where structure is known and where limited cleavages have been observed, a rational explanation can be put forward. FRED RICHARDS showed that ribonuclease could be split at a bond in a peptide loop that protrudes, and that the resulting two pieces of peptide chain would associate quite tightly with retention of structure and enzymatic function. As illustrated above in Figure 5, a similar limited fragmentation was observed with Staph. nuclease when the tightly bound ligands, $\mathrm{Ca}^{++}$and $\mathrm{pdTp}$, were present during trypsin digestion.

The fragments (6-49) and (50-149) associate to yield a complex with enzyme activity. Here we have another example of LANG and SCHELLMAN's "regions of varying stability."

To end up, I hope I have transmitted some of the feeling of nostalgia, and particularly of scientific indebtedness, that we alumni, and science in general, feel toward this institution. I speak for all of us when I wish MARTIN OTTESEN, and indeed the entire Carlsberg family of scientists and good providers, continuing success with both the new and the old facilities of this research center.

\section{REFERENCES.}

1. Arone, A., C. J. Bier, F. A. Cotton, E. E. Hazen, Jr., D. C. Richardson, J. S. Richardoson and A. YONATH: A high resolution structure of an inhibitor complex of the extracellular nuclease of staphylococcus aureus. I. Experimental procedures and chain tracing. J. Biol. Chem. 246: 2302-2316 (1971)

2. Bohnert, J. L. and H. TANiUChI: The examination of the presence of amide groups in glutamic acid and aspartic acid residues of staphylococcal nuclease (Foggi strain). J. Biol. Chem. 247: 4557-4560(1972)

3. Cone, J. L., C. L. Cusumano, H. Taniuchi and C. B. ANFinSEN: Staphylococcal nuclease (Foggi strain) II. The amino acid sequence. J. Biol. Chem. 246: 3103-3110(1971)

4. Epstein, H. F., A. N. Schechter, R. F. Chen and C. B. Anfinsen: Folding of nuclease: Kinetic studies of two processes in acid renaturation. J. Mol. Biol. 60: 499-508 (1971)

5. Taniuchi, H., C. B. Anfinsen, and A. Sodja: Nuclease-T: An active derivative of staphylococcal nuclease composed of noncovalently bonded peptide fragments. Proc. Nat. Acad. Sci. USA. 58: 1235-1242(1967)

6. Taniuchi, H., D. Davies and C. B. Anfinsen: A comparison of the $\mathrm{X}$-ray diffraction patterns of crystals of reconstituted nuclease- $T$ and of native staphylococcal nuclease. J. Biol. Chem. 247: 3362-3364 (1972) 